\title{
AIR QUALITY AND THE NUMBER OF URGENT INTERVENTIONS
}

\author{
CVITKOVIĆ ANTE ${ }^{1,2}$, BARIŠIN ANDREJA ${ }^{3}$, CAPAK KRUNOSLAV ${ }^{3}$, IVIĆ-HOFMAN IGOR ${ }^{1}$, \\ SONJA VIDIĆ ${ }^{4}$, POLJAK VEDRAN ${ }^{3}$, VALJETIĆ MARIJANA ${ }^{1} \&$ VEDRAN VAĐIĆ ${ }^{5}$ \\ ${ }^{1}$ Institute of Public Health of Brod-Posavina County, Croatia \\ ${ }^{2}$ Josip Juraj Strossmayer University of Osijek, Faculty of Medicine Osijek, Croatia \\ ${ }^{3}$ Croatian Institute of Public Health, Croatia \\ ${ }^{4}$ Meteorological and Hydrological Service, Croatia \\ ${ }^{5}$ Croatian Agency for the Environment and Nature, Croatia
}

\begin{abstract}
The purpose of this article is to analyse the correlation of air quality data with the number of emergency medical interventions and the number of patient visits to emergency clinic of the Integrated Emergency Hospital Admission (Croatian acronym: OHBP).

The analysis was conducted on data regarding Slavonski Brod (Croatia) from 1 January to 31 August 2016, obtained from:
\end{abstract}

(1) System eHitna - emergency medical services interventions

(2) Patients' visit to OHBP-General Hospital Slavonski Brod

(3) Environmental Protection Agency data regarding air quality for PM2.5, PM10 and $\mathrm{H}_{2} \mathrm{~S}$ per day.

The number of interventions ranged from 103 to $260(\mathrm{M}=151)$, and the number of patients from 90 to 250 per day $(M=133)$. Overall the number of interventions was 37,482 , and overall number of patients 32,757. The values of PM2.5 ranged from 1.73 to $500.11 \mu \mathrm{g} / \mathrm{m}^{3}(\mathrm{M}=18.70)$, values of PM10 ranged from 3.17 to $520.21 \mu \mathrm{g} / \mathrm{m}^{3}(\mathrm{M}=25.55)$, and values of $\mathrm{H} 2 \mathrm{~S}$ ranged from 0.62 to $12.43 \mu \mathrm{g} / \mathrm{m}^{3}(\mathrm{M}=1.49)$. The values of PM2.5, PM10 and H2S have been analysed also depending on the limit values $\left(25 \mu \mathrm{g} / \mathrm{m}^{3}\right.$ for PM2.5, $50 \mu \mathrm{g} / \mathrm{m}^{3}$ for PM10 and $5 \mu \mathrm{g} / \mathrm{m}^{3}$ for $\mathrm{H} 2 \mathrm{~S}$ ).

The values were within the limit values for PM2.5 in 64\% of days, in $80 \%$ of days for PM10 and in $93 \%$ of days for $\mathrm{H} 2 \mathrm{~S}$.

There was a statistically significant weak correlation $\left(\mathrm{r}_{\mathrm{s}}=0.333, \mathrm{p}<0.05\right)$ between PM2.5 and the number of patients per day, weak correlation $\left(\mathrm{r}_{\mathrm{s}}=0.334, \mathrm{p}<0.05\right)$ between PM10 and the number of patients per day and a weak correlation $\left(\mathrm{r}_{\mathrm{s}}=0.171, \mathrm{p}<0.05\right)$ between $\mathrm{H} 2 \mathrm{~S}$ and the number of patients per day.

There was a statistically significant difference in the number of patients who were provided with medical assistance in the day depending on the values of PM2.5 $(\mathrm{p}<0.001)$ and PM10 $(\mathrm{p}<0.001)$, while for $\mathrm{H} 2 \mathrm{~S}$ the significance was borderline $(\mathrm{p}=0.051)$.

Keywords: air pollution, particulate matter, urgent intervention.

\section{INTRODUCTION}

Air pollution from both outdoor and indoor sources represents the single largest environmental risk to health globally [1]. The enormous burden of disease due to air pollution is increasingly recognized by governments and institutions around the globe as a major public health concern [1]. WHO estimates that more than six million premature deaths were caused by air pollution exposure in 2012 [1]. Also, some 72\% of outdoor air pollution-related premature deaths were due to ischaemic heart disease and strokes, while $14 \%$ of deaths were due to chronic obstructive pulmonary disease or acute lower respiratory tract infections, and $14 \%$ of deaths were due to lung cancer [2]. The epidemiological evidence shows adverse effects of particulate matter following both short-term and long-term exposures [3].

PM10 and PM2.5 include inhalable particles that are small enough to penetrate the thoracic region of the respiratory system [4]. The health effects of inhalable PM are well 
documented. They are due to exposure over both the short term (hours, days) and long term (months, years) and include respiratory and cardiovascular morbidity, such as aggravation of asthma, respiratory symptoms and an increase in hospital admissions; and mortality from cardiovascular and respiratory diseases and from lung cancer [4]. There is good evidence of the effects of short-term exposure to PM10 on respiratory health, but for mortality, and especially as a consequence of long-term exposure [4]. PM2.5 is a stronger risk factor than the coarse part of PM10 (particles in the $2.5-10 \mu \mathrm{m}$ range) [4]. All-cause daily mortality is estimated to increase by $0.2-0.6 \%$ per $10 \mu \mathrm{g} / \mathrm{m}^{3}$ of PM10 [4]. Long-term exposure to PM2.5 is associated with an increase in the long-term risk of cardiopulmonary mortality by $6-13 \%$ per $10 \mu \mathrm{g} / \mathrm{m}^{3}$ of PM2.5 [4]. Susceptible groups with pre-existing lung or heart disease, as well as elderly people and children, are particularly vulnerable [4]. There is no evidence of a safe level of exposure or a threshold below which no adverse health effects occur [4]. The exposure is ubiquitous and involuntary, increasing the significance of this determinant of health [4].

Hydrogen sulphide is annoying with its smell [5]. The average value of the threshold odour according to WHO is $11 \mathrm{mg} / \mathrm{m}^{3}$ [5]. Long-term exposure to low concentrations of hydrogen sulphide is not completely investigated. A research among the workers in the water and wastewater network demonstrated an increased number of patients with obstructive lung disease in workers in the wastewater network, exposed to higher concentrations of hydrogen sulphide, with respect to workers employed in water network [6]. A research conducted near the paper mill, where the average annual concentration of hydrogen sulphide was $6 \mathrm{mg} / \mathrm{m}^{3}$, proved that the people who lived near the factory had 12 times more irritation than those who were not exposed to hydrogen sulphide [7].

Emergency admissions for ischemic heart disease and heart rhythm disturbances were significantly associated with PM10, PM2.5 and $\mathrm{NO}_{2}$ exposures the week before admission [8]. The estimated risk reduction for ischemic heart disease admissions was $2.44 \%, 2.34 \%$ and $3.93 \%$ for a $10 \%$ reduction in PM10, PM2.5 and $\mathrm{NO}_{2}$, respectively [8]. For Belgium, the associated annual cost savings were estimated at $€ 5.2$ million, $€ 5.0$ million and $€ 8.4$ million, respectively [8]. For heart rhythm disturbances, admission risk could be reduced by $2.16 \%$, $2.08 \%$ and $3.46 \%$ for a $10 \%$ reduction in PM10, PM2.5 and $\mathrm{NO}_{2}$, respectively [7]. This corresponds with a potential annual hospital cost saving in Belgium of €3.7 million, €3.6 million, and $€ 5.9$ million, respectively [8].

Annual reports on air quality in Slavonski Brod, Croatia, show that the atmosphere is polluted with respect to: H2S, PM10 and PM2.5 in 2015 [9]. A similar situation was in previous years [10]. The Oil Refinery Brod is one of the air polluters according to a report on the monitoring of air pollution [11]. According to annual air quality assessment reports it is identified that the significant contributor to the air pollution in this area is the Oil Refinery Brod installation located near the Sava river, across the border with Bosnia and Herzegovina [11]. This technologically outdated refinery was out of operation for many years. With its re-establishment eight years ago, air pollution problems started in the wider area of the city Slavonski Brod. The refinery is just across the Sava river and only $2 \mathrm{~km}$ away from Slavonski Brod in Croatia. This creates a lot of tension and the affected population is strongly protesting against pollution exceedances occurring daily during cold seasons. Accompanied with unfavourable meteorological conditions, long periods of low wind speed and stagnant air conditions, sensibility to consequences of air pollution problems became an everyday issue for local inhabitants. Health-related concerns became more and more noticeable and the odour nuisance an daily experience. 


\section{PURPOSE}

The purpose is to analyse the correlation of air quality data with the number of emergency medical interventions and the number of patient visits to emergency clinic of the Integrated Emergency Hospital Admission (Croatian acronym: OHBP).

\section{METHODS}

The analysis was conducted on data regarding Slavonski Brod (Croatia) from 1 January to 31 August 2016, obtained from:

(1) System eHitna (CAS - Central Ambulance Service) - emergency medical services interventions in Slavonski Brod (field interventions as well as patients' visits to emergency clinic),

(2) Patients' visit to OHBP-General Hospital Slavonski Brod,

(3) Meteorological and Hydrological Service data (Croatian acronym DHMZ) - data of the maximum and minimum temperature, high air pressure values and high relative humidity of air per day,

(4) Environmental Protection Agency data regarding air quality for PM2.5, PM10 and H2S per day from two measuring stations (SL1 and SL2).

Data from OHBP of GH Slavonski Brod were added to data from e-Hitna system, and they were observed in two ways: (1) sum of interventions/visits per day without clearing duplicate records and (2) sum of patients per day (interventions/visits with more than one appearance in eHitna and/or OHBP per patient per day are excluded). Corresponding meteorological data and data on air quality were added to each day. The limits for H2S, PM2.5 and PM10 are determined in accordance with the law of the Republic of Croatia and EU Directive on ambient air quality and cleaner air for Europe (2008/50/EC).

Numeric variables were described in the central values and dispersion measure, due to data distribution. Continuous variables were tested for normal distribution by Shapiro-Wilks's/ Kolmogorov-Smirnov-test. For testing the direction and strength of the association between variables, Pearson correlation coefficient was used for normally distributed variables and Spearman correlation coefficient in the case where variables were not normally distributed. The difference of continuous variables between the two groups was analysed by Mann-Whitney Wilcoxon test. SAS Enterprise Guide 7.1. was used for data processing. The Ethics Committee of the Croatian Institute for Public Health gave approval no. 80-436/1-16 to conduct the research.

\section{RESULTS}

Total number of patients analysed was 32,757 from 1 January to 31 August 2016. Out of this, at General hospital (OHBP), 27,810 patient visits and 4,947 at emergency medical services interventions (eHitna) were registered. The total number of medical interventions was 27,943 at General hospital (OHBP) and 9,539 at emergency medical services interventions (eHitna).

Measures of central tendency and variables dispersion are shown in Table 1.

The number of interventions in Slavonski Brod from 1 January to 31 August 2016, ranged from 103 to 260 interventions, provided at 90-250 patients per day. The median of N_patient_Day was 133, and the median of the number of interventions per day was 151 (N_Intervention).

Minimum temperatures were in the range of -11 to $20^{\circ} \mathrm{C}$ with a median value of $8^{\circ} \mathrm{C}$, while the maximum temperature was -7 to $36^{\circ} \mathrm{C}$ with a median of $21^{\circ} \mathrm{C}$. The pressure ranged 
Table 1: Measures of central tendency and variables dispersion.

\begin{tabular}{lccrrrrr}
\hline Variable & \multirow{2}{*}{ N } & Mean & Std & Median & Min & Max & N \\
\cline { 3 - 6 } & & & Dev & & & & Miss \\
\hline N_patient_Day & 244 & 134.25 & 19.12 & 132.5 & 90 & 250 & 0 \\
N_Intervention & 244 & 153.61 & 24.26 & 151 & 103 & 260 & 0 \\
N_Intervention_ & 244 & 39.09 & 15.35 & 35 & 15 & 89 & 0 \\
Emergency clinic & & & & & & & \\
N_Intervention_OHBP & 244 & 114.52 & 15.71 & 114 & 78 & 200 & 0 \\
N_patient_Day_ & 244 & 20.27 & 7.16 & 19 & 7 & 51 & 0 \\
Emergency clinic & & & & & & & \\
N_patient_Day_OHBP & 244 & 113.98 & 15.68 & 113 & 78 & 199 & 0 \\
Temp min & 244 & 7.8 & 7.27 & 8 & -11 & 20 & 0 \\
Temp max & 244 & 19.66 & 9.13 & 21 & -7 & 36 & 0 \\
Air pressure_medium & 244 & 1,004 & 6.76 & $1,004.45$ & 985.6 & $1,023.8$ & 0 \\
Relative_humidity_ & 244 & 74.68 & 10.82 & 75 & 38 & 97 & 0 \\
medium & & & & & & & \\
SL1_PM2.5 & 244 & 34.29 & 47.8 & 18.7 & 1.73 & 500.11 & 0 \\
SL2_PM2.5 & 230 & 26.8 & 29.71 & 16.01 & 2.33 & 235.1 & 14 \\
SL1_PM10 & 244 & 41.17 & 49.55 & 25.55 & 3.17 & 520.21 & 0 \\
SL2_PM10 & 227 & 31.62 & 28.4 & 21.8 & 0.38 & 239.15 & 17 \\
SL1_H2S & 237 & 1.97 & 1.59 & 1.49 & 0.62 & 12.43 & 7 \\
SL2_H2S & 163 & 3.3 & 1.73 & 3.11 & 0.69 & 16.68 & 81 \\
\hline
\end{tabular}

from 985.6 to $1,023.8 \mathrm{hPa}$ with a median $1,004.45 \mathrm{hPa}$, while the medium humidity ranged from 38 to $97 \%$ with a median of $75 \%$. At the measurement station SL1, PM2.5 values ranged from 1.73 to $500.11 \mu \mathrm{g} / \mathrm{m}^{3}$ with a median of $18.70 \mu \mathrm{g} / \mathrm{m}^{3}$, PM10 values ranged from 3.17 to $520.21 \mu \mathrm{g} / \mathrm{m}^{3}$ with a median of $25.55 \mu \mathrm{g} / \mathrm{m}^{3}$, and $\mathrm{H} 2 \mathrm{~S}$ values ranged from 0.62 to $12.43 \mu \mathrm{g} / \mathrm{m}^{3}$ with a median of $1.49 \mu \mathrm{g} / \mathrm{m}^{3}$. At the measurement station SL2, PM2.5 values ranged from 2.33 to $235.10 \mu \mathrm{g} / \mathrm{m}^{3}$ with a median of $16.01 \mu \mathrm{g} / \mathrm{m}^{3}$, PM10 values ranged from 0.38 to $239.15 \mu \mathrm{g} / \mathrm{m}^{3}$ with a median of $21.80 \mu \mathrm{g} / \mathrm{m}^{3}$ and $\mathrm{H} 2 \mathrm{~S}$ values ranged from 0.69 to 16.68 $\mu \mathrm{g} / \mathrm{m}^{3}$ with a median of $3.11 \mu \mathrm{g} / \mathrm{m}^{3}$. The values of PM2.5, PM10 and H2S were also analysed depending on the limit values ( $25 \mu \mathrm{g} / \mathrm{m}^{3}$ for PM2.5, $50 \mu \mathrm{g} / \mathrm{m}^{3}$ for PM10 and $5 \mu \mathrm{g} / \mathrm{m}^{3}$ for H2S).

The values at the measurement station SL1 in 64\% (156 days) were within the limit values for PM2.5, in 80\% for PM10 (194 days) and in 93\% (226 days) for H2S, while at the station SL2, values were within the recommended range in 65\% (159 days) for PM2.5, in $80 \%$ for $\mathrm{PM} 10$ and in $58 \%$ for $\mathrm{H} 2 \mathrm{~S}$. The share of days for which measurements were not recorded at the measuring station SL2 for PM2.5 and PM10 is $6 \%$ and 7\%, while the share of H2S days for which measurements are not recorded is $13 \%$.

The number and proportion of days at stations SL1 and SL2 when the values were within the limits and higher than recommended and the number of patients examined during these days are shown in Figs. 1-4. 


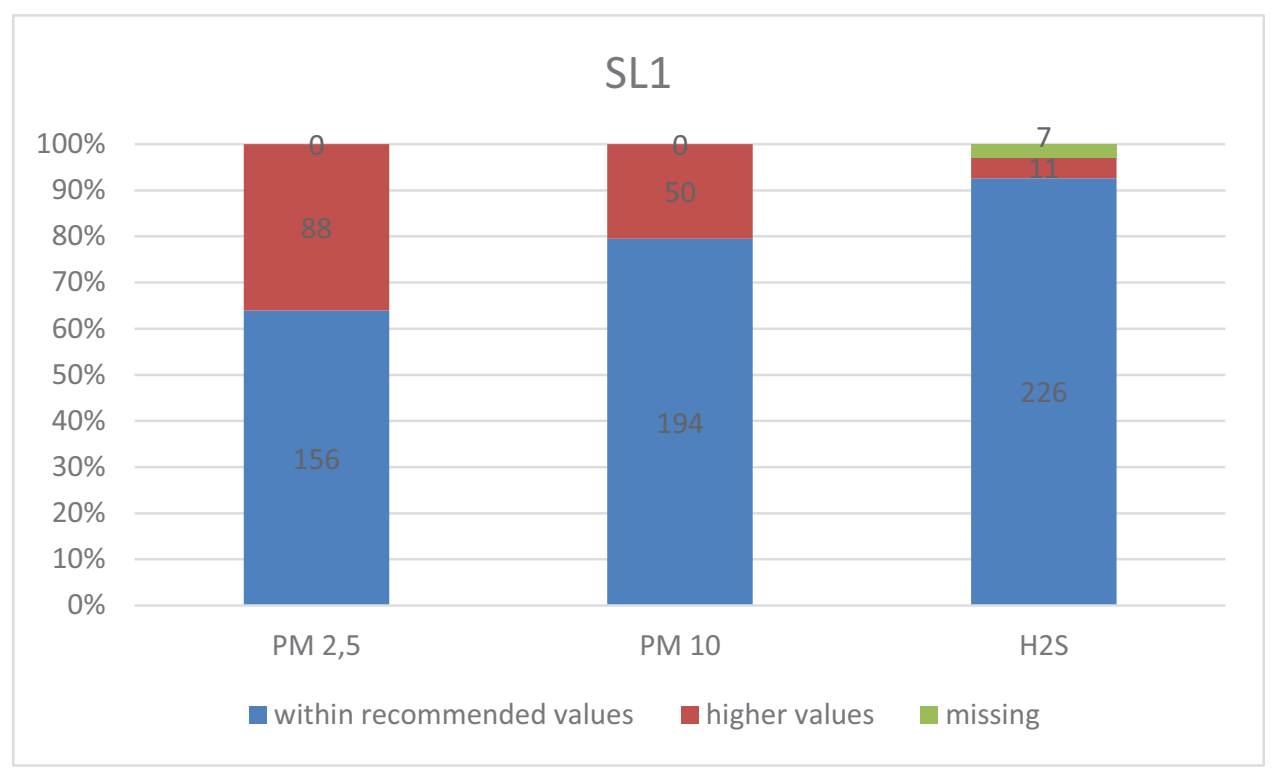

Figure 1: Number of days within or out of limits, measuring station SL1.

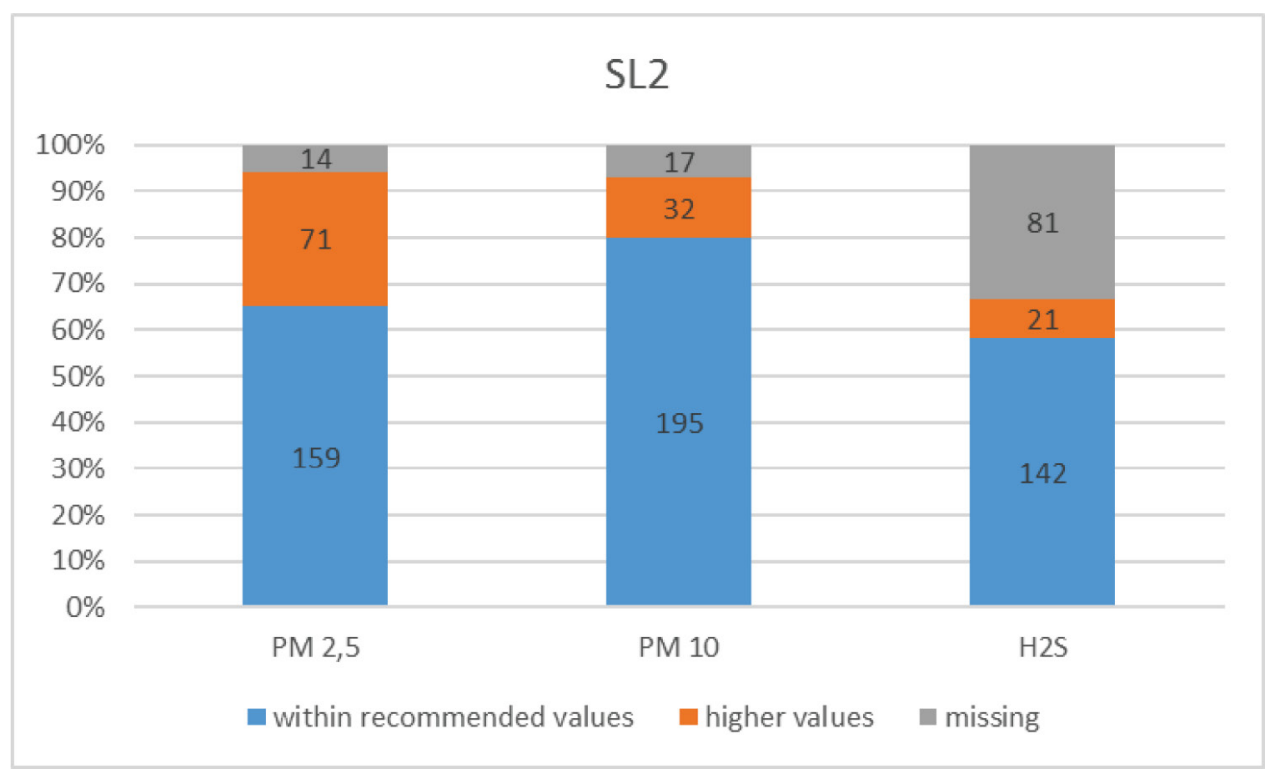

Figure 2: Number of days within or out of limits, measuring station SL2.

In Table 2, there is the correlation between the number of interventions/visit and environmental variables (meteorological data and data on PM2.5, PM10 and H2S), and the significant correlation with the level of significance of $5 \%(\mathrm{p}<0.05)$. 


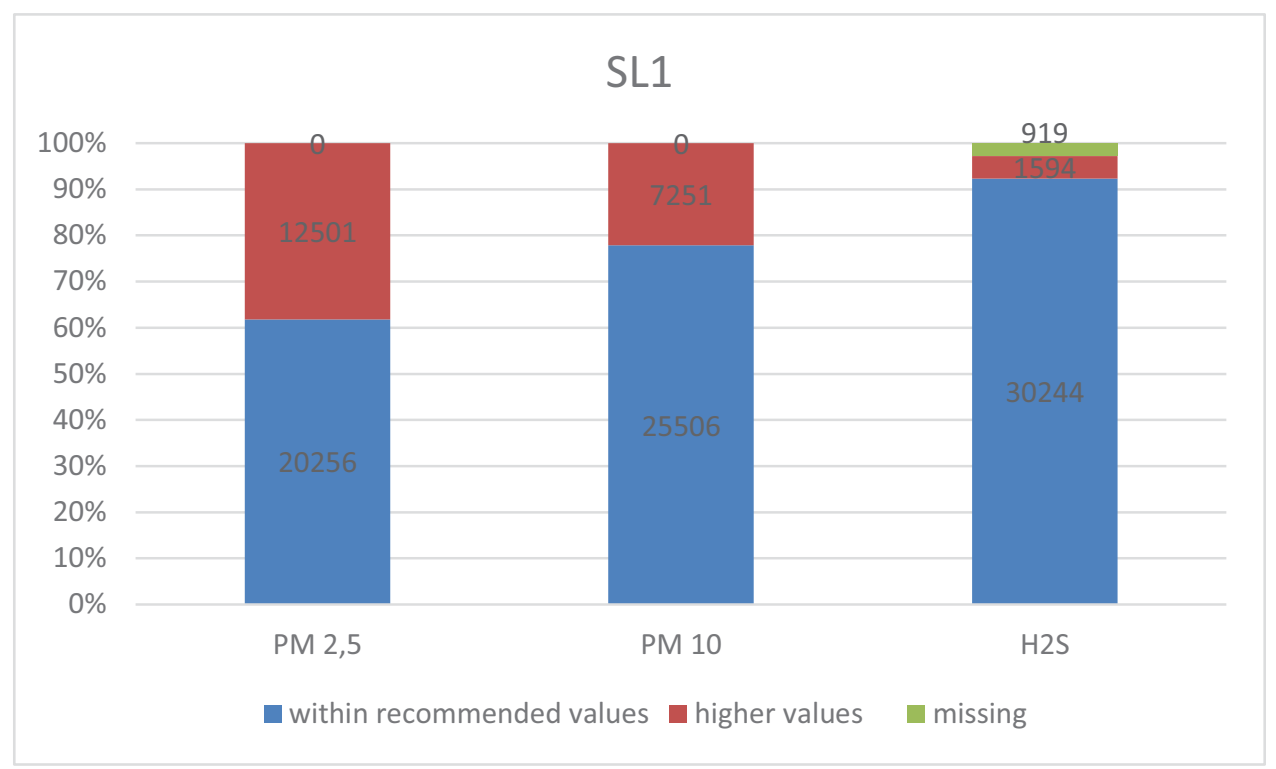

Figure 3: Number of patients on days within or out of limits, measurement station SL1.

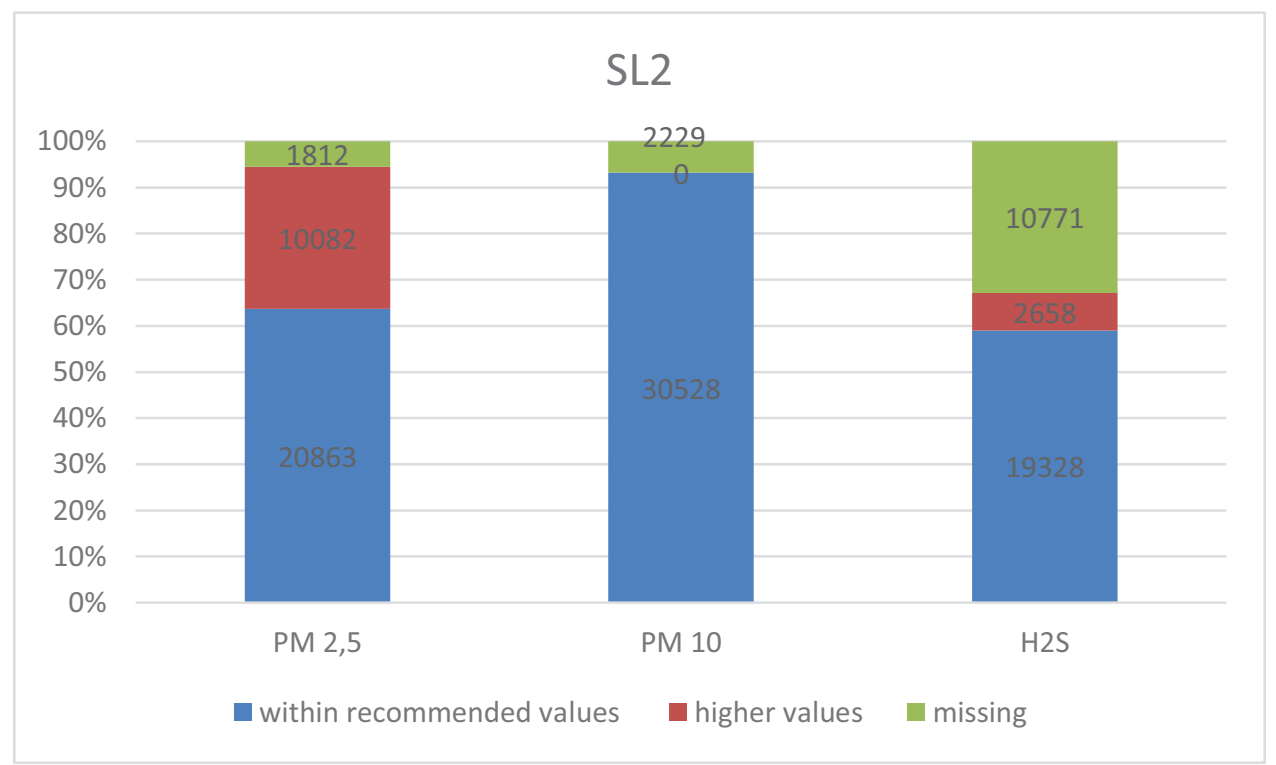

Figure 4: Number of patients on days within or out of limits, measurement station SL2.

There was a significant weak negative correlation ( $r s=-0,241, \mathrm{p}<0.05)$ between the minimum temperature and the number of patients per day, and a statistically significant weak negative correlation $(\mathrm{rs}=-0,149, \mathrm{p}<0.05)$ between the maximum temperature and the number of patients per day. At the measuring station SL1, there was significant weak correlation ( $r s=0.333, p<0.05)$ between PM2.5 and the number of patients per day, a weak correlation 
Table 2: The correlation between the number of interventions/visits and environmental variables.

\begin{tabular}{|c|c|c|c|c|}
\hline & \multicolumn{2}{|c|}{ Number of patients per day } & \multicolumn{2}{|c|}{ Number of interventions per day } \\
\hline & $\begin{array}{l}\text { Correlation } \\
\text { coefficient }\end{array}$ & $\mathrm{p}$ & $\begin{array}{l}\text { Correlation } \\
\text { coefficient }\end{array}$ & $\mathrm{p}$ \\
\hline Relative_humidity_medium & -0.097 & 0.131 & 0.01 & 0.874 \\
\hline Temp min & -0.241 & 0.001 & -0.035 & 0.585 \\
\hline Temp max & -0.149 & 0.02 & 0.055 & 0.395 \\
\hline Air pressure_medium & 0.054 & 0.399 & 0.019 & 0.773 \\
\hline SL1-PM2.5 & 0.333 & $<0.001$ & 0.107 & 0.095 \\
\hline SL2-PM2.5 & 0.324 & $<0.001$ & 0.101 & 0.128 \\
\hline SL1-PM10 & 0.334 & $<0.001$ & 0.119 & 0.063 \\
\hline SL2-PM10 & 0.349 & $<0.001$ & 0.157 & 0.018 \\
\hline SL1-H2S & 0.171 & 0.008 & 0.105 & 0.107 \\
\hline SL2-H2S & -0.243 & 0.002 & -0.159 & 0.043 \\
\hline
\end{tabular}

( $\mathrm{rs}=0.334, \mathrm{p}<0.05)$ between the PM10 and the number of patients per day and weak correlation ( $\mathrm{rs}=0.171, \mathrm{p}<0.05$ ) between $\mathrm{H} 2 \mathrm{~S}$ and the number of patients per day. At the measuring station SL2, there was significant weak correlation ( $r s=0.324, p<0.05$ ) between PM2.5 and the number of patients per day, a weak correlation ( $r s=0.349, \mathrm{p}<0.05)$ between the PM10 and the number of patients per day and significant weak negative correlation ( $\mathrm{rs}=$ $-0.243, \mathrm{p}<0.05$ ) between $\mathrm{H} 2 \mathrm{~S}$ and the number of patients per day, as well as weak negative correlation ( $\mathrm{rs}=-0.159, \mathrm{p}<0.05)$ with the number of interventions per day. The correlation value at SL2 should be interpreted with caution due to the large proportion of the days when the measurements were not carried out (33\%).

Depending on the values of PM2.5, PM10 and H2S, the number of patients was compared on the days when the values at SL1 were out of or within the limits. There was a statistically significant difference in the number of patients on the days depending on the values of PM2.5 $(\mathrm{p}<0.001)$ and PM10 $(\mathrm{p}<0.001)$, while for H2S, significance was borderline $(\mathrm{p}=0.051)$.

\section{DISCUSSION}

Results of this study show positive, statistically significant, but weak correlation between PM2.5 and PM10 concentrations and daily number of patients' visits registered with emergency medical services (eHitna) and General Hospital in Slavonski Brod. Number of patients' visits increased with the increase of concentration levels. Similar results have been obtained in some other research studies [12, 13].

Pollutants have short-term and long-term effects on health. The connection between the concentrations of PM2.5, PM2.5-10, PM10 and their chemical constituents (soluble ions) with hospital admissions due to circulatory and respiratory diseases among the elderly in a medium-sized city in Brazil is well known [14]. Risks of hospitalization increased by $23.5 \%$ and $12.8 \%$ per $10 \mu \mathrm{g} / \mathrm{m}^{3}$ of PM2.5-10 and PM10, respectively. PM2.5 exhibited a significant association with circulatory system diseases, with the risk of hospitalization increasing by $19.6 \%$ (95\% CI: $6.4 ; 34.6$ ) per $10 \mu \mathrm{g} / \mathrm{m}^{3}$ [14].

Exposure to PM2.5 elevated the hospitalization four and five days after exposure. A 10 $\mu \mathrm{g} / \mathrm{m}^{3}$ decrease in concentration would imply 256 less hospital admissions and savings of 
approximately $\mathrm{R} \$ 220,000$ in a medium-sized city [15]. Other studies also show the connection between particulate matter and hospital admissions due to stroke as well as between children pneumonia and air pollution $[16,17]$. Certain pollution is associated with elevated hospital admissions due to respiratory diseases and ischemic stroke [18, 19].

The highest number of admissions (37.2\%) occurred during winter, followed by autumn with $2,367(24.1 \%)$, spring with $2,347(23.9 \%)$ and summer with $1,446(14.7 \%$; $p<0.001)$ [17]. The maximum, minimum and mean temperatures were associated similarly with the number of hospitalization [20].

Weak negative correlation between minimum/maximum temperature and the daily number of patients reporting to the emergency clinic, specifically in the winter months at low temperature and low wind events, can be partially explained with increased heating on wood and charcoal a common way of heating by the local population. People with chronic cardiovascular diseases do not feel comfortable at low temperature that is often the trigger for sudden deterioration of the disease. In such weather episodes patients could go directly to their general practitioners or they might stay at home - this could be the reason for weak negative correlation between minimum/maximum temperatures and the daily number of emergency patients.

In Croatia, the emergency health service is organized through a system of emergency clinic and the Integrated Emergency Hospital Admission. Although we did not specifically analyse the specific reason why patients visit emergency service, connections with high concentrations of PM10 and PM2.5 were established. The authors are not aware of any similar studies in Croatia. These results provide basis for further recommendations and on the continuation of investigation that would lead to an adequate advisory system for general public in cases of pollutant concentrations exceeding prescribed threshold or guideline limits.

Some countries have introduced recommendations such as the Air Quality Index [21] with recommendations on how to proceed when certain concentrations of pollutants. Although in Croatia such recommendations do not exist to such extent (Croatian Agency for Environment and Nature publishes the index without description of health impacts), certain cities might start applying them in order to reduce the number of interventions. It would be beneficial if citizens were informed on elevated concentrations of air pollutants, especially PM, as well as on their influence on health, namely on daily basis. Such information should serve as a recommendation on how to act and avoid unnecessary exposure. One possibility might also be to inform citizens is through the County 112 Centre. Croatian legislation regulates use of 112 systems for public warning in the case of elevated $\mathrm{SO}_{2}$ and $\mathrm{NO}$ concentrations, but not for the elevated levels of PM10 and PM2.5.

Specific health advice/warning information for the general public and sensitive individuals (those with pre-existing illness and the elderly) is developed already [21]. It is based on the level of the Daily Air Quality Index and are disseminated via Internet [21]. In the United Kingdom, national and regional/community/urban communication systems are the channels used to inform population on air quality levels on a daily basis including health-related recommendations for individuals sensitive to air pollution and for general public [21].

Considering constraints (lack of data on residence, lack of measurement significantly expressed at the measuring station 2) and specifics of the sample (the domain of emergency medicine and the logging of visits), test strength and generalization of conclusions on for the entire population of Slavonski Brod can be limited.

It is necessary to continue with further research, to jointly interpret the results of complementary surveys and to analyse further additional parameters and indicators of current pollution. 


\section{CONCLUSION}

Conducted research in the area of Slavonski Brod in the period from 1 January to 31 August 2016 showed statistically significant, although weak, correlation of temperature, PM 2.5, PM 10 and $\mathrm{H} 2 \mathrm{~S}$ with the number of patients provided with daily emergency assistance. Temperature correlation was negative, PM 2.5 and PM 10 correlation was positive or the number of patients increased when the parameter values were elevated, while in the case of H2S, correlation was inconsistent. A statistically significant difference was found in the number of patients provided with emergency assistance on days when the exceedance of PM 2.5, PM 10 and $\mathrm{H} 2 \mathrm{~S}$ values has been observed, namely, the number of patients was higher on days with elevated concentration values.

\section{ACKNOWLEDGEMENTS}

Pavle Jeličić, Vlado Josić, Nataša Janev, Marko Brkić, Ivan Pristaš, Tamara Poljičanin and Borna Pleše from Croatian Institute of Public Health contributed in this study with the preparation and interpretation of statistical analysis of epidemiological data. Results shown in this study are a part of the study of impact of environmental factors on human health which is financed by Ministry of Health of the Republic of Croatia.

\section{REFERENCES}

[1] Evolution of WHO Air Quality Guidelines: Past, Present and Future. WHO Regional Office for Europe: Copenhagen, available at www.euro.who.int/data/assets/pdf file/0019/331660/Evolution-air-quality.pdf?ua=1 (accessed 20 February 2017).

[2] World Health Organisation (WHO), www.who.int/mediacentre/factsheets/fs313/en/ (accessed 16 February 2017).

[3] Review of Evidence on Health Aspects of Air Pollution - REVIAHAPP Project, Technical Report. WHO Regional Office for Europe: Copenhagen, available at http://www. euro.who.int/_data/assets/pdf_file/0004/193108/REVIHAAP-Final-technical-reportfinal-version.pdf?ua=1 (accessed 15 February 2017).

[4] Health Effects of Particulate Matter. Policy Implications for Countries in Eastern Europe, Caucasus and Central Asia. WHO Regional Office for Europe: Copenhagen, available at http://www.euro.who.int/_data/assets/pdf_file/0006/189051/Healtheffects-of-particulate-matter-final-Eng.pdf?ua=1, 2013 (accessed 10 February 2017).

[5] Hydrogen Sulfide: Human Health Aspects (Concise International Chemical Assessment Document 53). WHO: Geneva, available at http://www.who.int/ipcs/publications/cicad/ en/cicad53.pdf (accessed 25 February 2017).

[6] Partti-Pellinen, K., Marttila, O., Vilkka, V., Jaakkola, J., Jäppinen, P. \& Haahtela, T., Effects of low level exposure to malodorous sulfur compounds on symptoms. Archives of Environmental Health: An International Journal, 51(4), pp. 315-320, 1996. DOI: 10.2105/AJPH.20.6.598.

[7] Jaakkola, J., Vilkka, V., Marttila, O., Jäppinen, P. \& Haahtela, T., The South Karelia Air Pollution Study. The effects of malodorous sulfur compounds from pulp mills on respiratory and other symptoms. The American Review of Respiratory Disease, 142(6 Pt 1), pp. 1344-1350, 1990. DOI: 10.1164/ajrccm/142.6_Pt_1.1344

[8] Devos, S., Cox, B., Dhondt, S., Nawrot, T. \& Putman, K. Cost saving potential in cardiovascular hospital costs due to reduction in air pollution. The Science of the Total Environment, 527-528, pp. 413-419. DOI: 10.1016/j.scitotenv.2015.04.104, 2015. 
[9] Godišnje izvješće za praćenje kvalitete zraka na području Republike Hrvatske za 2015. godinu. Zagreb; Hrvatska agencija za okoliš i prirodu, available at http://iszz.azo.hr/ iskzl/datoteka?id=31863 (accessed 10 February 2017).

[10] Godišnja izvješća o praćenju kvalitete zraka na području Republike Hrvatske. Zagreb; Agencija za zaštitu okoliša, available at http://iszz.azo.hr/iskzl/godizvrpt. $\mathrm{htm}$ ?pid=0\&t=0 (accessed 10 February 2017).

[11] Izvještaj o praćenju onečišćenja zraka na privremenoj postaji državne mreže za praćenje kvalitete zraka- Slavonski Brod (Za razdoblje 7. studenog 2013. - 8. kolovoza 2014.). Zagreb;Institut za medicinska istraživanja i medicinu rada, Jedinica za higijenu okoline, available at http://iszz.azo.hr/iskzl/datoteka?id=19830 (accessed 1 February 2017).

[12] Liu, P., Wang, X., Fan, J., Xiao, W. \& Wang, Y., Effects of air pollution on hospital emergency room visits for respiratory diseases: Urban-suburban differences in Eastern China. International Journal of Environmental Research and Public Health, 13(3), p. 341, 2016. DOI: 10.3390/ijerph13030341.

[13] Zheng, X.Y., Association between air pollutants and asthma emergency room visits and hospital admissions in time series studies: A systematic review and meta-analysis. PLoS One, 10(9), p. e0138146. DOI: 10.1371/journal.pone.0138146, eCollection 2015.

[14] Ferreira, T.M., Forti, M.C., de Freitas, C.U., Nascimento, F.P., Junger, W.L. \& Gouveia, N. Effects of particulate matter and its chemical constituents on elderly hospital admissions due to circulatory and respiratory diseases. International Journal of Environmental Research and Public Health, 13(10): 947, 2016. DOI: 10.3390/ijerph13100947.

[15] Patto, N.V., Nascimento, L.F., Mantovani, K.C., Vieira, L.C. \& Moreira, D.S. Exposure to fine particulate matter and hospital admissions due to pneumonia: Effects on the number of hospital admissions and its costs. Revista Da Associacao Medica Brasileira (1992), 62(4), pp. 342-346, 2016. DOI: 10.1590/1806-9282.62.04.342.

[16] Huang, F., et al., Particulate matter and hospital admissions for stroke in Beijing, China: Modification effects by ambient temperature. Journal of the American Heart Association, 5(7), p. e003437, 2016. DOI: 10.1161/JAHA.116.003437.

[17] Souza, L.S., Air pollutants and hospital admission due to pneumonia in children: A time series analysis. Revista Da Associacao Medica Brasileira (1992), 62(2), pp. 151-156, 2016. DOI: 10.1590/1806-9282.62.02.151.

[18] Phung, D. et al., Air pollution and risk of respiratory and cardiovascular hospitalizations in the most populous city in Vietnam. Sci Total Environ, 557-558, pp. 322-330, 2016. DOI: 10.1016/j.scitotenv.2016.03.070.

[19] Alimohammadi, H., Fakhri, S., Derakhshanfar, H., Hosseini-Zijoud, S.M., Safari, S. \& Hatamabadi, H.R. The effects of air pollution on ischemic stroke admission rate. Chonnam Medical Journal, 52(1), pp. 53-58, 2016. DOI: $10.4068 / \mathrm{cmj}$.

[20] Almagro, P., Hernandez, C., Martinez-Cambor,P., Tresserras, R., Escarrabill, J., Seasonality, ambient temperatures and hospitalizations for acute exacerbation of COPD: A population-based study in a metropolitan area. Int J Chron Obstruct Pulmon Dis, 10, pp. 899-908, 2015. DOI: 10.2147/COPD.S75710.

[21] UK_Defra., The Daily Air Quality Index, UK Department for Environment, Food and Rural Affairs: London, available at http://uk-air.defra.gov.uk/air-pollution/daqi (accessed 20 February 2017). 